\title{
ANTROPOLOGIA DA LIBERDADE E EXISTÊNCIA ÉTICA
}

\author{
ANTHROPOLOGY OF FREEDOM AND ETHICAL EXISTENCE
}

Bruno Magalhães Costa*

\section{RESUMO}

No presente trabalho examinamos a maneira pela qual, na filosofia de Tomás de Aquino, os componentes antropológicos atualizam as potências da alma possibilitando ao homem ser o princípio de suas ações, responsável por elas e constituir-se, em seu desenvolvimento dinâmico, como ente de existência ética. São esses componentes antropológicos que conferem ao homem a potência para desenvolver os hábitos virtuosos que lhe servem de meios para alcançar sua plena autorrealização. Utilizamos a metodologia de leitura analítica, análise e comparação dos textos da Suma teológica, pois nela encontramos a elaboração do sistema antropológico e ético do Aquinate. A pessoa humana é dotada de todas as condições antropológicas necessárias para desenvolver-se em uma existência ética.

PALAVRAS-CHAVE: Inteligência. Liberdade. Existência ética. Tomás de Aquino.

\section{RÉSUMÉ}

Dans le cadre de ce travail-ci, on a pour but d'examiner la manière par laquelle, au sein de la philosophie thomiste, les composants anthropologiques actualisent les puissances de l'âme, tout en rendant possible à l'homme d'être le principe de ses actions, d'en assumer la responsabilité e de se constituer, à la lumière de son processus d'épanouissement dynamique, en tant qu'être de l'existence éthique. Ce sont ces composants anthropologiques qui confèrent à l'homme la puissance de développer des habitus vertueux qui lui serviront de moyens pour atteindre sa pleine réalisation. On utilise la méthodologie de la lecture analytique, de l'analyse et comparaison des textes de la Somme Théologique, car on y rencontre l'élaboration du système anthropologique et éthique de l'Aquinate. La personne humaine est douée de toutes les conditions anthropologiques nécessaires au but de se développer dans une existence éthique.

MOTS-CLÉ : Intelligence. Liberté. Existence éthique. Thomas d'Aquin.

\footnotetext{
* Graduado em filosofia pela PUC Minas. E-mail: brunomc.the@gmail.com.
} 


\section{INTRODUÇÃO}

Tomás de Aquino estabelece, na Suma teológica ${ }^{1}$, os componentes antropológicos sobre os quais fundamenta sua perspectiva ética. Neste trabalho procuramos nos deter na relação que o Angélico faz entre tais elementos e a existência ética pela qual o homem se torna senhor de seus atos e se dispõe à sua plena autorrealização.

O homem constitui-se como um ente que está em constante formação. Não está finalizado, mas em movimento, em processo, em desenvolvimento do seu ser até a plenitude de suas possibilidades de autorrealização. Isso significa que a autorrealização do homem permanece sempre aberta num horizonte que ele busca alcançar, mas que só fruirá no gozo da eterna bem-aventurança.

É por ser um ente racional e livre que o homem se constitui portador dos elementos fundamentais que lhe possibilitam ser senhor de si e orientar-se teleologicamente para o fim deliberado, de maneira autônoma, podendo ser responsabilizado por tais atos e constituir-se como ente cuja existência pode ser dita ética e moral.

\section{A ANTROPOLOGIA DA LIBERDADE}

Tomás de Aquino concebe sua antropologia a partir da unidade substancial corpoalma; não dois compostos, mas um único composto formado a partir de duas essências unidas de modo substancial. A dimensão corporal é dotada de todas as condições necessárias que possibilitam à alma humana atualizar suas potências e ordenar suas ações em vista de um fim refletidamente escolhido. Em seu processo de desenvolvimento e formação ética, o homem, racional e livre, pode dirigir-se à sua autorrealização de maneira livre, consciente e deliberada.

Segundo Vaz (2009) o ponto de partida da ética de Tomás de Aquino é exatamente a análise filosófico-teológica da práxis antropológica humana racional e livre pela qual o homem pode deliberar, eleger e operar a sua autorrealização, isto é, a formação ética da pessoa é possibilitada pelo processo de atualização das potências intelectivas.

Nascimento (2011) comenta que, na segunda parte da Suma teológica, Tomás de Aquino busca estabelecer a medida pela qual o homem é princípio de suas ações, capaz de decisão livre e autodomínio. Tendo considerado na primeira parte da Suma os componentes

\footnotetext{
${ }^{1}$ Nas citações, identificaremos a obra com a abreviação STh seguida da localização da passagem referida.
} 
antropológicos com os quais o homem é dotado, na segunda parte, Aquino fala sobre aquilo que o homem pode tornar-se, através de suas escolhas e do seu modo de agir. A base da argumentação do Aquinate não será o homem "pronto", perfeito, saído das mãos de Deus, mas o homem em seu processo dinâmico de formação, em um caminho que ele mesmo pode construir no mundo, porque é capaz e autônomo.

Uma primeira discussão que se faz necessária é sobre a questão 6 da primeira seção da segunda parte da referida obra, que trata do voluntário e involuntário nos atos humanos. Vejamos com detalhes.

Considerando que o homem tem por seu fim último a sua plena autorrealização, e é isso que postula o Aquinate (STh, IaIIae, q. 1-5), é preciso que aquele saiba como chegar a tal fim, ou seja, o que ele deve fazer, que caminhos deve tomar para chegar a esse destino. Em outras palavras, é preciso eleger os atos que servem de meio proporcional para alcançar o referido fim, pois tudo que se ordena a um fim deve ser proporcional a tal fim (STh, IaIIae, q. 7). Definir os meios faz parte de um bom planejamento estratégico para se alcançarem os objetivos desejados. Toda boa escolhe exige que, eleito o fim, se definam os meios necessários.

O homem, para alcançar seus objetivos, precisa eleger comportamentos que sejam suficientes e possíveis ao seu repertório de modo que lhe possibilitem alcançar tal meta. Nesse contexto, o Aquinate apresenta (STh, IaIIae q. 6) dois tipos de comportamentos humanos: a) os que são próprios do homem, e por isso são voluntários, produzidos pela vontade, enquanto apetite racional, que o levam a agir por si mesmo, deliberando sobre os meios e conduzindose ao fim, o que garante a liberdade e autonomia da pessoa; b) e outros que ele tem em comum com os demais animais, chamados de paixões. Ora, como a autorrealização é própria do homem, nosso autor conclui que é pelo exercício dos comportamentos propriamente humanos que o homem alcança sua plena autorrealização e, portanto, permitem que seja aplicado o conceito de moralidade a esses atos que lhe são próprios. Os outros animais não conhecem com perfeição o fim de seus comportamentos, sendo levados pelo instinto, sem deliberação racional.

Dizer que um comportamento humano é voluntário significa que estão implicados dois dos princípios essenciais dos atos humanos: a consciência do fim que se deseja alcançar, pela potência racional, e a busca desse fim, pela potência da vontade. Ora, desse modo, com quanto mais clareza o homem conhece o fim ao qual tende e as consequências advindas com tal comportamento, com mais liberdade de consciência move-se a si mesmo e a 
voluntariedade mais se manifesta em tais atos. Assim, diz-se que ele possui o domínio de seus atos e pode, portanto, ser responsabilizado por eles (STh, IaIIae, q. 6, a.1).

Tomás de Aquino entende que o conhecimento do fim pode ser de dois modos: perfeito e imperfeito. Os animais irracionais possuem certo conhecimento do fim a que tendem com alguns comportamentos, mas esse conhecimento é imperfeito, pois não sabem por que tendem a esse fim. Ao ser humano cabe a possibilidade de chegar ao conhecimento perfeito do fim que busca, pois possui uma natureza racional que apreende tanto sua meta, quanto o motivo pelo qual busca essa meta. Desse modo lhe é possível deliberar sobre seus atos, considerando que a vontade é capaz de mover-se a fins diversos, pois a razão pode eleger fins opostos (STh, IaIIae, q. 6, a2).

Importante apontar que, para o Aquinate (STh, IaIIae, q. 6, a.7; q. 9-10), mesmo o voluntário sendo um ato do apetite intelectivo (da vontade) que é movido pelo intelecto ${ }^{2}$, o desejo sensível pode contribuir para aumentar a voluntariedade de determinado ato. Ora, é fato que a vontade pode inclinar-se para aquilo que é desejado pelo apetite sensível, pelas emoções. Assim, se um homem está sob uma paixão, pode julgar conveniente e bom orientarse a um fim ao qual não se moveria caso não estivesse sob tal padecimento.

Outro elemento importante para essa questão moral dos atos humanos é o papel que o Angélico (STh, IaIIae, q.6, a8) delega ao intelecto para definição da possibilidade de voluntariedade ou involuntariedade do ato humano. Com isso, nosso autor reconhece que a consciência na execução de ato é exigida para sua determinação moral, e que a ignorância (desde que não seja voluntária e desejada), por privar o homem do conhecimento que se requer, pode levá-lo a comportamentos que sejam involuntários. Assim, por exemplo, a omissão, desatenção, desconhecimento ou má interpretação de informações pode levar à involuntariedade no comportamento de infringir normas regulamentadas pela sociedade (OLIVEIRA; BOLIVETO, 2012).

A vontade é a potência apetitiva do intelecto que permite ao homem realizar suas escolhas e, por isso, os comportamentos humanos propriamente ditos são chamados de voluntários. O querer do homem é livre, por isso ele pode querer ou não querer algo (STh, IaIIae, q. 13, a6). Assim, o homem, enquanto dotado de um querer livre e voluntário, age deliberando, ou seja, comparando entre muitas coisas que ele quer, investigando sobre aquilo

\footnotetext{
2 Tomás de Aquino assume a postura do intelectualismo grego que postula a orientação da vontade pelo intelecto, ou seja, a vontade é movida pela razão de bem apreendida pelo intelecto, como pode ser observado em STh IaIIae, q. 9, a1.
} 
que deve ser feito, pensando, refletindo, escolhendo, querendo. Isso significa que a escolha pressupõe uma reflexão, uma deliberação, para só depois tomar uma decisão (STh, IaIIae, q. 14).

Veiga (2017) sintetiza essa questão propondo que o homem delibera avaliando os meios, as possibilidades de escolha, podendo escolher uma delas. Essa escolha é uma ação da vontade, associada à inteligência que revelou à vontade a razão de bem daquilo que devia escolher. Essa atividade implica que o homem seja a causa de seus próprios atos.

\section{A BONDADE E A MALÍCIA DOS ATOS HUMANOS}

Considerados os comportamentos humanos voluntários, cabe-nos ao momento refletir sobre a concepção de Tomás de Aquino sobre o valor moral de tais atos, ou seja, sua bondade e malícia.

O Aquinate (STh IaIIae, q. 18, a1) considera que os comportamentos humanos podem ser de três tipos: a) indiferentes; b) bons; c) maus. Seu ponto de partida para essa definição é a concepção metafísica de que ser e bondade se convertem ${ }^{3}$, ou seja, tudo aquilo que é, tem algo de bondade. Desse modo, para que algo seja plenamente bom é necessário que seja composto de todos os elementos que lhe convêm. O mal não é por si, mas segundo a carência de ser e de bondade nas coisas, conforme suas capacidades. Considerando os atos humanos, se lhes falta algo devido à ação humana, será dito deficiente de ser, e, consequentemente, mau. A total ausência de bem corresponderia à total deficiência de ser. Logo, o mal absoluto não existe. O que chamamos de ação moralmente má é, na verdade, uma ação deficiente ou carente de bem.

Tomás de Aquino (STh, IaIIae, q. 18) enumera os elementos que podem configurar uma ação enquanto deficiente de bem: objeto (a2), circunstâncias (a3), fim (a4) e espécie (a5). O fim que se busca é o objeto da intenção, propriedade da vontade que faz uma coisa tender a outra. Ora, é pela intenção do fim que o homem elege os meios necessários e suficientes, assim, quem quer os fins quer também os meios, estes, por sua vez, são fins intermediários que podem ser necessários para alcançar o fimm último (STh, IaIIae, q. 12).

A ética das virtudes de Tomás de Aquino nos revela que viver bem é sinônimo de proceder bem e, para isso, não basta fazer coisas boas, é preciso considerar o modo de fazer bem as coisas boas. Decidir-se em fazer bem as coisas não é suficiente, o importante é

\footnotetext{
${ }^{3}$ A questão pode ser mais bem aprofundada relendo o que Tomás de Aquino escreve sobre o mal na questão 48 da I parte da Suma.
} 
decidir-se racionalmente, e não só por um impulso. Isso significa que o homem precisa ter bem presente a real intenção de estar fazendo uma ação boa. Essa deliberação é dada pelo fim que a vontade quer (GILSON, 1951).

O Aquinate apresenta, na sequência, o Tratado das paixões da alma (STh, IaIIae, q. 22 a 48). As paixões, contradizendo os estoicos, não são doenças da alma, mas dizem respeito àquilo que lhe advém, com transmutação corporal $^{4}$, de modo passivo, sem a participação direta da razão e da vontade, inclinando a determinado bem ou afastando de certo mal. Como dizem respeito ao movimento do apetite irracional — concupiscível e irascível — do ponto de vista moral, por si mesmas, as paixões não são boas nem más, sua moralidade é considerada apenas quando estão sob o império da razão e da vontade, ou seja, quando a paixão torna-se um movimento reconhecido, refletido, assumido e voluntário (STh, IaIIae, q.24, a1).

As paixões podem fazer com que a bondade do ato seja diminuída, caso ofusquem o juízo da razão; ou aumentada, caso o homem, pela reflexão, escolha e favoreça a si ser afetado por uma ou outra paixão de modo que seja movido mais prontamente pelo apetite sensível a um bem eleito pela razão. Convém, de fato, à perfeição moral, que os comportamentos humanos sejam conduzidos ao bem, não só pelas potências da razão e da vontade, mas também pelo apetite sensitivo. O homem deve praticar o bem com todo o seu ser, com gosto, com prazer, pois o exercício moral do homem não consiste apenas em ordenar seu comportamento público, mas ordenar racionalmente suas paixões conforme o seu fím último (STh, IaIIae, q. 24, a3; q. 33, a4).

\section{AS VIRTUDES NA CONSTITUIÇÃO DE UMA EXISTÊNCIA ÉTICA}

Seguiremos por considerar o próximo tratado da Suma teológica que nos ajuda a compreender o pensamento do Aquinate sobre a existência ética: o tratado dos hábitos e das virtudes (STh, IaIIae, q. 49-67).

Para Vaz (2009), o tratado dos hábitos exposto na Suma teológica permite que a teoria da antropologia da liberdade possa ser conjugada com a inserção do sujeito no universo da existência ética, enquanto manifestação de um modo de ser ao qual os hábitos conferem permanência e crescimento. Por isso, nos deteremos agora nessa seção da obra.

\footnotetext{
${ }^{4}$ Daí Tomás de Aquino (STh, IaIIae, q. 22, a. 1) afirmar que a paixão é dita da alma apenas acidentalmente, porque o sujeito é o composto.
} 
O que é um hábito? Para se falar de hábito, é necessário que o sujeito do qual se fala tenha potências para várias possibilidades de ação, caso contrário não é possível falar no desenvolvimento de hábitos. Assim, o Aquinate explica que os corpos celestes, por exemplo, não podem ter hábito, porque seu movimento não admite outra possibilidade de ser. Hábito é uma qualidade, ou seja, algo acrescido e não substancial, que compete aos seres que têm potências para muitas coisas ( $S T h$, IaIIae, q. 49, a4). Como a alma é o princípio da ação, é preciso que os hábitos existam na alma conforme as suas potências. Mas em quais potências?

As potências vegetativas não têm possibilidades de várias ações, nem estão sob o império da razão e da vontade, logo não apresentam hábitos. As potências sensíveis, por si, estão ordenadas apenas às pulsões, logo elas não possuem hábitos, mas, se estão ordenadas sob o império da razão, podem se ordenar a diversos fins e, por conseguinte, desenvolver os hábitos (STh, IaIIae, q. 50, a3). Entretanto, é no intelecto possível que estão os hábitos, pois ele tem potências para muitas coisas (a4).

Veiga (2017), comentando o referido tratado, apresenta os hábitos como uma prontidão, facilidade, disposição adquirida pela repetição voluntária de determinados atos que produzam uma certa facilidade para agir, em momentos semelhantes, da mesma forma. Por isso, Tomás de Aquino classifica os hábitos como qualidade da alma que a predispõe a agir de determinada forma. Esses hábitos podem estar em harmonia com o fim da plena realização do homem, daí ele é chamado de virtude, ao passo que, se não está, é chamado de vício.

Tomás de Aquino, ao tratar das virtudes (STh, IaIIae, q. 55, a1), refere-se a elas enquanto a perfeição máxima que o hábito alcançou. Ora, é pelo hábito que as variadas possibilidades de ações humanas passam de potência ao ato; logo, as virtudes, enquanto fim último das potências, são os atos humanos levados à máxima perfeição a que se destinam pelo intelecto. Desse modo, a virtude diz respeito ao bem enquanto fim último, pois todo mal implica deficiência, por isso toda virtude é um hábito bom que aperfeiçoa o homem a agir bem e que lhe possibilita desenvolver suas capacidades antropológicas à plena realização como pessoa humana (q. 55, a3; q. 58, a3).

Segundo Vaz (2009), é pela virtude que o homem avança progressiva e continuamente à sua meta de plena realização. Considerando que o homem tem a potência para vir a ser, falamos da atualização de sua perfeição própria enquanto sujeito racional e livre. O exercício das virtudes possibilita ao homem chegar a ser o que ele tem de possibilidades para ser, conforme sua constituição antropológica. Nesse sistema, a virtudes atualizam, facultam e possibilitam ao homem que ele chegue ao seu pleno desenvolvimento humano. Ser perfeito, 
na linguagem de Tomás de Aquino, é chegar à plenitude das possibilidades de realização, ou seja, chegar ao fim que lhe convém, segundo o seu ser.

O Aquinate defende que os hábitos estão na alma, conforme as suas potências. De modo absoluto estão na vontade, porque ela é que move ao ato, ou noutras potências enquanto movidas pela vontade (STh, IaIIae, q. 56, a3), o que permite considerar que possam estar também no apetite sensível (irascível e concupiscível), quando não atuam pela pulsão natural, como também no intelecto (STh, IaIIae, q. 50).

Quanto às virtudes, é importante considerá-las como hábitos que estão em ato e não só em potência. Como as virtudes implicam a perfeição de uma potência, pois são uma disposição para o melhor enquanto fim, elas estão, necessariamente, na vontade ou noutras potências enquanto movidas por ela. Ora, o intelecto pode ser movido pela vontade, logo ele pode ser sujeito das virtudes.

Desse modo, Tomás de Aquino elabora a correspondência entre as potências da alma e as virtudes desenvolvidas. Assim, a virtude da fé está no intelecto especulativo. O intelecto prático é o sujeito da prudência ( $S T h$, IaIIae, q. 56, a3). Quanto às potências apetitivas, são aperfeiçoadas pelas virtudes morais (STh, IaIIae, q. 59, a4). No que diz respeito aos apetites irascível e concupiscível, enquanto ordenados pela vontade, podem ser igualmente sujeitos da virtude, pois podem tornar-se princípios dos atos humanos; assim, o irascível é sujeito da fortaleza e o concupiscível é sujeito da temperança (STh, IaIIae, q. 56, a4; q. 60, a4). A vontade, por sua vez, como apetite intelectivo que ordena tudo para o bem enquanto fim, não necessita de ser aperfeiçoada por uma virtude, a menos que ela queira um bem que ultrapasse seu querer, ou seja, quando diz respeito a um outro, por isso, ela é sujeito das virtudes que ordenam os afetos do homem para um além-de-si: Deus ou outro indivíduo. As virtudes que assim operam são a religião, a piedade, a gratidão, a caridade e a justiça (STh, IaIIae, q. 56, a6; q. 60, a3).

Quanto às potências apreensivas sensíveis, Tomás de Aquino (STh, IaIIae, q. 56, a5) não lhes admite possuírem virtudes, pois o conhecimento da verdade a que se destinam tais potências nunca será perfeito, cabendo esse conhecimento ao intelecto.

No tratado das virtudes, Tomás de Aquino integra ao patrimônio ético clássico dos gregos a tradição ética cristã. Nesta, para que as virtudes sejam aperfeiçoadas requer-se um auxílio divino: as bem-aventuranças, os dons e os frutos do Espírito Santo. Ou seja, a vida teologal, coroada pela ação divina, alimenta e leva as virtudes à efetivação prática. $\mathrm{O}$ organismo das virtudes, considerando o exercício das virtudes e o auxílio da graça, torna-se, 
assim, a constituição ordinária da existência ética que orienta o homem pelo caminho melhor: o caminho da caridade que direciona o homem a um fim que transcende os limites da existência natural, apontam para seu fim sobrenatural. Em razão disso, é possível falar que as considerações do Aquinate apontam para uma ética do amor, em sua forma mais autêntica e gratuita, na qual estão envolvidas inteligência e vontade na contemplação, enquanto ato ético por excelência (VAZ, 2009).

O Aquinate postula, e nosso trabalho corrobora com essa ideia, que o homem é possuidor de todas as condições necessárias, segundo seu grau de ser, para chegar, com a prática das virtudes adquiridas pelos hábitos, a tornar-se senhor de si e, consequentemente, um sujeito cuja existência possa ser dita ética e moral.

\section{CONSIDERAÇÕES FINAIS}

Enquanto ente de existência corporal e espiritual, o homem é um composto formado a partir de duas essências: corpo e alma. Seu corpo tem todas as características que possibilitam às potências da alma serem plenamente atualizadas. Sua alma possui potências que configuram as operações próprias do homem: inteligência e livre-arbítrio, possibilitando-lhe ser princípio de suas ações, possuir o livre-arbítrio, ter o domínio de si e dirigir-se voluntariamente, ordenando suas ações a um fim.

Essa concepção antropológica de Tomás de Aquino fundamenta toda a sua elaboração ética, que está ordenada ao exercício das potências intelectivas a serem atualizadas em busca da ação melhor, mais excelente, pela prática dos hábitos virtuosos.

Em Tomás de Aquino, a antropologia é pressuposto metafísico fundamental para a elaboração de sua ética. Compreendendo a natureza do homem, enquanto ser de potências, de vir a ser, de inteligência e vontade, afetado pelas paixões, o Angélico propõe que o ser humano é dotado de todas as condições necessárias para conduzir-se, de maneira autônoma, a uma existência ética, virtuosa e ser responsável por seus atos.

\section{REFERÊNCIAS}

GILSON, Etienne. El tomismo: introducción a la filosofía de santo Tomás de Aquino. Versión castellana de Alberto Oteiza Quirno. Buenos Aires: Desclée, de Brouwer, 1951.

NASCIMENTO, Carlos Arthur Ribeiro do. Um mestre no ofício: Tomás de Aquino. São Paulo: Paulus, 2011. (Como ler filosofia). 
OLIVEIRA, Terezinha; BOLIVETO, Laís. O homem é o senhor de suas ações: a concepção de escolha em Tomás de Aquino e Jean-Paul Sartre. Filosofia Unisinos, São Leopoldo, 13(3), p. 422-431, set-dez., 2012. Disponível em:

http://revistas.unisinos.br/index.php/filosofia/article/viewFile/fsu.2012.133.06/1232 Acesso em: 26 set. 2019.

TOMÁS DE AQUINO. Suma teológica. Tradução de Vanuucchi et al. 2. ed. São Paulo: Loyola, 2011.

VAZ, Henrique Cláudio de Lima. Escritos de filosofia IV: introdução à Ética Filosófica I. 5. ed. São Paulo: Loyola, 2009.

VEIGA, Bernardo. A ética das virtudes segundo Tomás de Aquino. Campinas: Ecclesiae, 2017. 